\title{
Viabilidade de Microcápsulas com Lactobacillus acidophilus Armazenadas em Temperatura Ambiente
}

Mariana de Araújo Etchepare (I), Greice Carine Raddatz (I), Gabriela Poletto (I), Maria Fernanda da Silveira Cáceres de Menezes (I), Augusto Tasch Holkem (I), Thaiane Marques da Silva (I), Carlos Pasqualin Cavalheiro (I), Alexandre José Cichoski (I), Caro Caroline Posser Simeoni (I), Cristiano Ragagnin de Menezes

(I) UFSM - Universidade Federal de Santa Maria (Santa Maria-Avenida Roraima)

\section{Resumo}

A microencapsulação compreende um conjunto de diversas técnicas que permitem o desenvolvimento de formulações, em que o seu conteúdo é protegido das condições adversas do meio e liberado em sítios de ação específicos, em quantidade e momento adequado para exercer a função desejada. O objetivo deste trabalho foi avaliar a viabilidade de microcápsulas com Lactobacillus acidophilus durante estocagem em temperatura ambiente. A produção das microcápsulas foi realizada através da técnica de extrusão/aspersão. Foram preparadas três soluções distintas: a primeira solução contendo $1 \%$ de alginato de sódio (ALG),a segunda contendo $1 \%$ de alginato de sódio $+1 \%$ de Hi-maize (prebiótico) (AHM) e a terceira contendo $1 \%$ de alginato de sódio $+1 \%$ de Hi-maize (prebiótico) que recebeu tratamento com quitosana (AHQ). O probiótico utilizado foi o Lactobacillus acidophilus. As microcápsulas foram armazenadas úmidas e estocadas em temperatura de $25^{\circ} \mathrm{C}$. Visando determinar o tempo de viabilidade das micropartículas, a enumeração de células viáveis foi realizada a cada 15 dias, num período de 135 dias de estocagem. Ao longo dos 135 dias, o número de células viáveis de Lactobacillus acidophilus para todos os tratamentos foi acima de $106 \log$ UFC/g, estando dentro dos

\footnotetext{
Referência:

Mariana de Araújo Etchepare, Greice Carine Raddatz, Gabriela Poletto, Maria Fernanda da Silveira Cáceres de Menezes, Augusto Tasch Holkem, Thaiane Marques da Silva, Carlos Pasqualin Cavalheiro, Alexandre José Cichoski, Caro. Viabilidade de Microcápsulas com Lactobacillus Acidophilus Armazenadas em Temperatura Ambiente. In: Anais do $12^{\circ}$ Congresso Latinoamericano de Microbiologia e Higiene de Alimentos - MICROAL 2014 [= Blucher Food Science Proceedings, num.1, vol.1]. São Paulo: Editora Blucher, 2014. 
padrões exigidos para que ocorram os benefícios exercidos pelos probióticos. No entanto, o tratamento AHM ao longo de 120 dias mantevese estável com melhor viabilidade apresentando diferenças significativas ( $\mathrm{p}$ $<0,05)$ entre os demais tratamentos sendo que após 135 dias, apresentou uma pequena redução fazendo com que o tratamento AHQ se destacasse com melhor viabilidade ao nível de $\mathrm{p}<0,05$. Estes resultados sugerem que a microencapsulação de Lactobacillus acidophilus La-14 em microcápsulas utilizando alginato de sódio como principal material de revestimento, pode aumentar a sobrevivência celular durante a estocagem em temperatura ambiente e que a proteção pode ser significativamente melhorada se houver a adição de um prebiótico e/ou prebiótico + quitosana na formulação da cápsula. Sendo assim, acredita-se que é possível armazenar essas microcápsulas em temperatura ambiente, tornando assim o armazenamento viável em locais onde as instalações de refrigeração são limitadas, considerando também a redução dos custos.

Palavras-Chave: alginato, armazenamento, microencapsulação, probiótico, viabilidade

Agência de Fomento: 